\title{
Correction to: Assessment of uncertainties in projected temperature and precipitation over the Arabian Peninsula: a comparison between different categories of CMIP3 models
}

\author{
Mansour Almazroui $^{1}$ - Sajjad Saeed ${ }^{1,2} \cdot$ M. Nazrul Islam ${ }^{1}$ - M. Salman Khalid ${ }^{1}$ • \\ Abdulrahman K. Alkhalaf ${ }^{1} \cdot$ Ramzah Dambul $^{1}$
}

Published online: 23 September 2017

(c) Springer International Publishing AG 2017

\section{Correction to: Earth Syst Environ (2017) 1:12 DOI 10.1007/s41748-017-0012-z}

The article was published online without the latest corrections of the author.

In abstract we replaced 3.28 with 3.82: $3.82 \pm 1.47$ $(5.36 \pm 1.47){ }^{\circ} \mathrm{C}$. In Sect. 3.3 we replace 3.28 with 3.82 : $2.32 \pm 2.45,3.49 \pm 2.49$ and $3.82 \pm 1.47{ }^{\circ} \mathrm{C}$. And we publish a updated Figs. 12 and 15 (see below).

The original article was corrected.

The online version of the original article can be found under doi:10.1007/s41748-017-0012-z.

Mansour Almazroui

mansour@kau.edu.sa

1 Center of Excellence for Climate Change Research/ Department of Meteorology, King Abdulaziz University, P.O. Box 80234, Jeddah 21589, Saudi Arabia

2 Department of Earth and Environmental Sciences, KU Leuven, Louvain, Belgium 
$2021-2050$

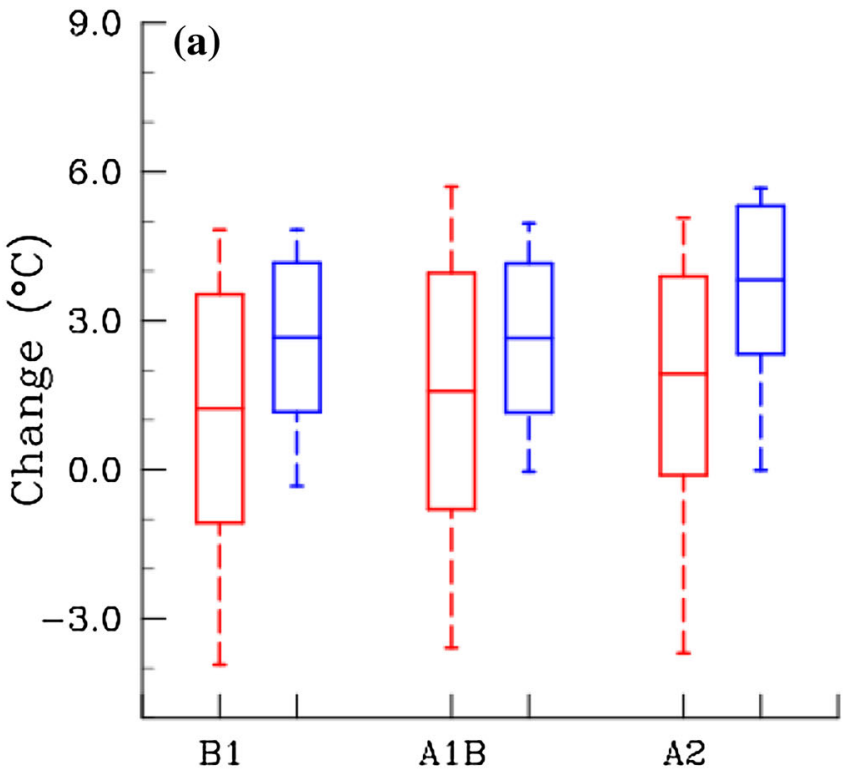

Fig. 12 The Box-and-Whisker plots show the domain averaged temperature change over the Arabian Peninsula for the future periods a 2021-2050 and b 2070-2099 w.r.t. the base period 1970-1999 for all models (red) and best performing models (blue). The band in the box represents the change in MME mean, the bottom (top) of the box

\section{$2070-2099$}

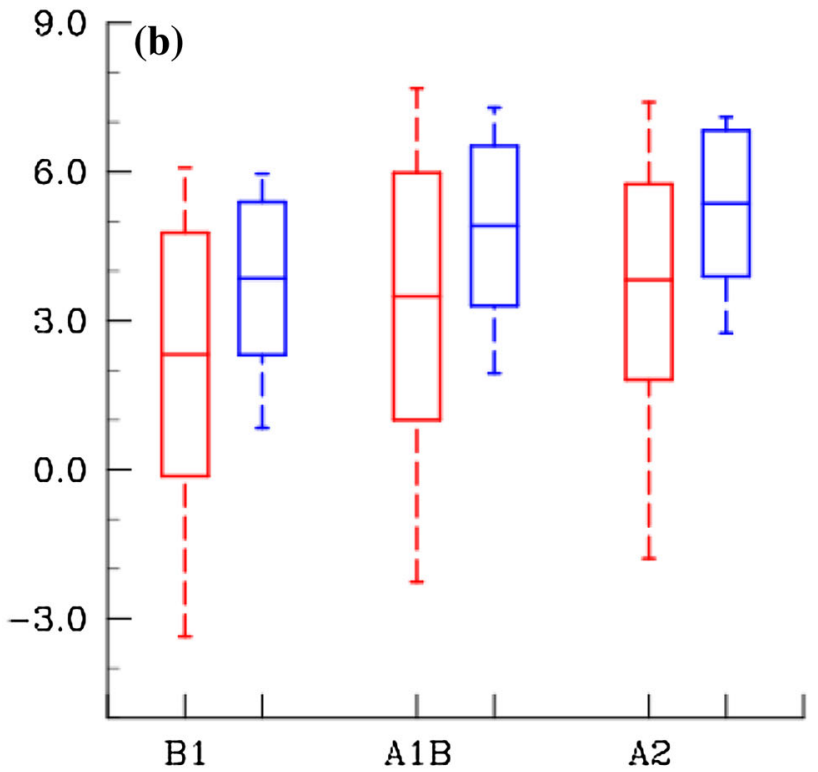

represents the MME mean SAT change \pm 1 inter-model standard deviation. The ends of the Whiskers represent the inter-model range i.e. multi-model maximum and minimum change w.r.t. base period MME mean simulation values 

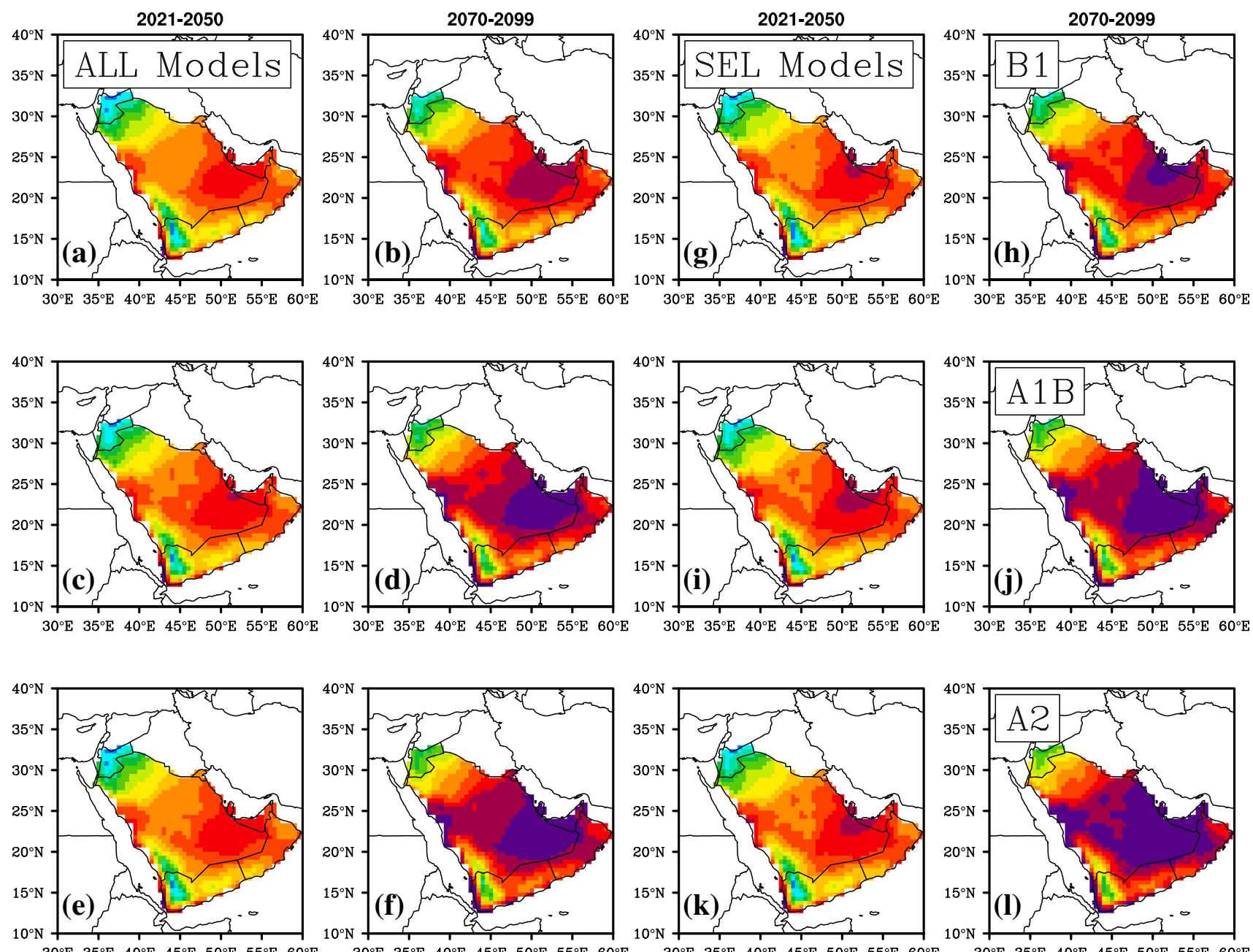

$30^{\circ} \mathrm{E} 35^{\circ} \mathrm{E} \quad 40^{\circ} \mathrm{E} \quad 45^{\circ} \mathrm{E} 50^{\circ} \mathrm{E} 55^{\circ} \mathrm{E} 60^{\circ} \mathrm{E}$

$30^{\circ} \mathrm{E} 35^{\circ} \mathrm{E} \quad 40^{\circ} \mathrm{E} \quad 45^{\circ} \mathrm{E} 50^{\circ} \mathrm{E} 55^{\circ} \mathrm{E} 60^{\circ} \mathrm{E}$

$30^{\circ} \mathrm{E} 35^{\circ} \mathrm{E} 40^{\circ} \mathrm{E} \quad 45^{\circ} \mathrm{E} 50^{\circ} \mathrm{E} 55^{\circ} \mathrm{E} 60^{\circ} \mathrm{E}$

$30^{\circ} \mathrm{E} 35^{\circ} \mathrm{E} \quad 40^{\circ} \mathrm{E} \quad 45^{\circ} \mathrm{E} 50^{\circ} \mathrm{E} 55^{\circ} \mathrm{E} 60^{\circ} \mathrm{E}$

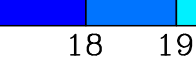

\section{0}

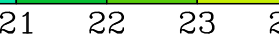

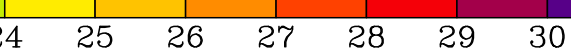

Fig. 15 MME mean corrected future temperature (units: ${ }^{\circ} \mathrm{C}$ ) for all models (first and second columns) and selected best performing models (third and fourth columns) 